$10 \mathrm{IKC}-21$

\title{
DIAMOND-BEARING TERRIGENOUS ROCKS: KEY ROLE IN PREDICTION AND EXPLORATION OF BURIED DEPOSITS
}

\author{
Ustinov V.N. \\ alrosaspb@mail.ru, ALROSA, Saint-Petersburg, Russia
}

\section{INTRODUCTION}

The majority of world diamond production $(80 \%)$ is mined from deposits which are confined to so-called open (exposed) territories, where kimberlite (and lamproite) bodies or placers occur near the surface. Nowadays main activities are concentrated within these areas, which represent relatively simple exploration environments. But during the last the 17 years, no deposits of worldwide importance have been discovered. Prospective areas for the discovery of buried kimberlite bodies and diamond placers occur at the margins of synclinoriums, grabens and other tectonic depressions within cratons of ancient platforms. However, exploration activity targeted to discovery of buried deposits is minimal in the world (except Siberian and East-European platforms). The reasons for this are not only the higher costs of this type of exploration, but also the lack of sufficiently developed exploration techniques. The potential of geophysical, geochemical, heavy mineral concentrate and other methods used on exposed territories is substantially limited in the areas with deeply buried deposits. Therefore, the investigations of sedimentary rocks containing kimberlite indicator mineral (KIM) dispersion haloes, trains and placers becomes one of the main prediction and exploration tools in these areas. The research presented here is based on results of work in the Siberian, East-European and African provinces.

\section{DESCRIPTION OF THE RESEARCH}

Diamond-bearing terrigenous rocks (Fig. 1) are characterized by definite lithologic, stratigraphic, mineralogical, facies dynamic, paleogeomorphologic and morphogenetic features

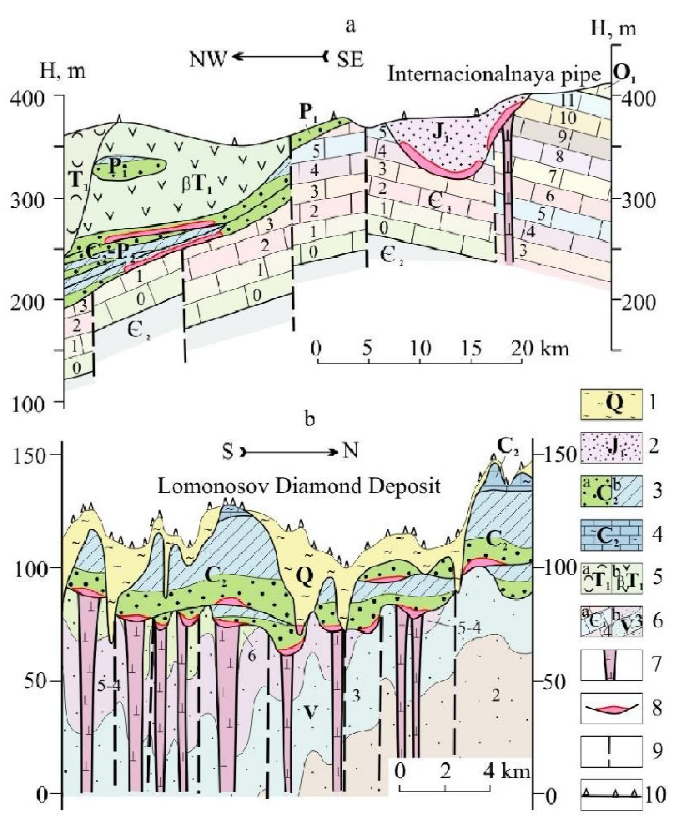

Fig. 1. Terrigenous diamond-bearing rocks overlaying kimberlite pipes in Siberian (a) and East-European (b) platforms. 1-4terrigenous diamond-bearing rocks: 1-Quaternary, 2-Mesozoic, 3Upper Paleozoic (a-regressiver, b-transgressive sequences); 4 Upper Paleozoic carbonaceous barren rocks; 5 - Mesozoic intrusive and volcanic rocks ( $\mathrm{a}$ - dolerites, $\mathrm{b}$ - tuffs); 6 - Lower Paleozoic (a) and Upper Proterozoic (b) kimberlite containing strata and numbers of layers; 7 - Middle Paleozoic kimberlite pipes; 8 - buried kimberlite indicator minerals dispersion haloes and diamond placers; 9 - faults; 10 - boreholes. 


\section{0 $^{\text {th }}$ International Kimberlite Conference, Bangalore - 2012}

distinctive of the evolutionary development of primary sources and placers. Lithologic, stratigraphic and mineralogical research reveal epochs of erosion of primary sources and formation of diamond placers of certain ages that give the chance to provide targeted exploration. Lithologic and stratigraphic investigations are the first stage of studying terrigenous diamondbearing rocks, providing detailed information from sections that allows correlation to regional stratigraphic scales utilizing lithologic, paleontological and geophysical (gamma-ray and magnetic logging) methods, correlation of coeval levels in an area, tracing of marker horizons for paleogeomorphological reconstructions and correlation of cyclic sedimentation formed in continental or basin (marine) conditions.

Analysis of mineral associations in terrigenous rocks serves as an additional instrument for determining timecorrelative deposition, allowing estimation of then existing relief and specific features of the source rocks, and in a number of cases serves as an exploration tool. For example, the presence of saponite in sediments may testify to the proximity of kimberlite bodies undergoing erosion.

Formation times of "productive" horizons correlate well with changes of the World Ocean level (Fig. 2), regressions and transgressions of which coincided in time with directions of regional basin fluctuations. Erosion of kimberlite bodies and concentration of KIM in terrigenous sediments took place at specific time intervals, dependent on the superposition of the effects of simultaneous unidirectional eustatic changes of the World Ocean level and tectonic movements of regional scale. The more intense the contemporaneous effects of global and regional factors, the better the resulting deposits are in terms of diamond grade, overall size is and consequently industrial significance. This regularity may be used as a tool of prediction and exploration for buried diamond placers.

Facies dynamics and paleogeomorphologic

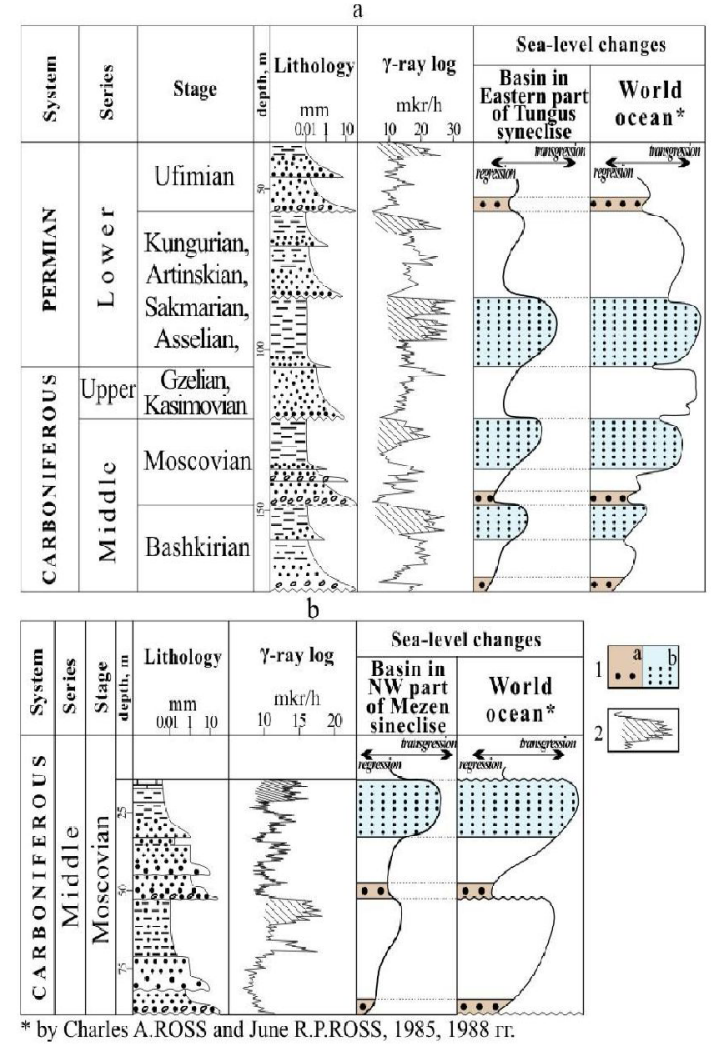

Fig. 2. Stages of formation of kimberlite indicator minerals dispersion haloes and diamond placers based on research of Late Paleozoic terrigenous rocks on the Siberian (a) and East-European (b) platforms.

reconstructions give the chance to classify buried haloes and dispersion trains of KIM according to their position in an ancient relief, environment of formation and dynamic type of terrigenous rocks. They reveal morphogenetic types of haloes, which can be used to reconstruct transportation avenues of kimberlitic minerals and to outline the areas and distribution of diamond sources (Fig. 3).

Paleogeomorphological and facies dynamic modelling allow step-by-step reconstruction of paleorelief at the time of KIM halo formation, interpretation of the origin of halo shape, evaluation of depth of erosion of primary sources and investigation of facies, dynamics, and paleohydrochemical conditions of sedimentation of timecorrelative deposits. 


\section{0 $^{\text {th }}$ International Kimberlite Conference, Bangalore - 2012}

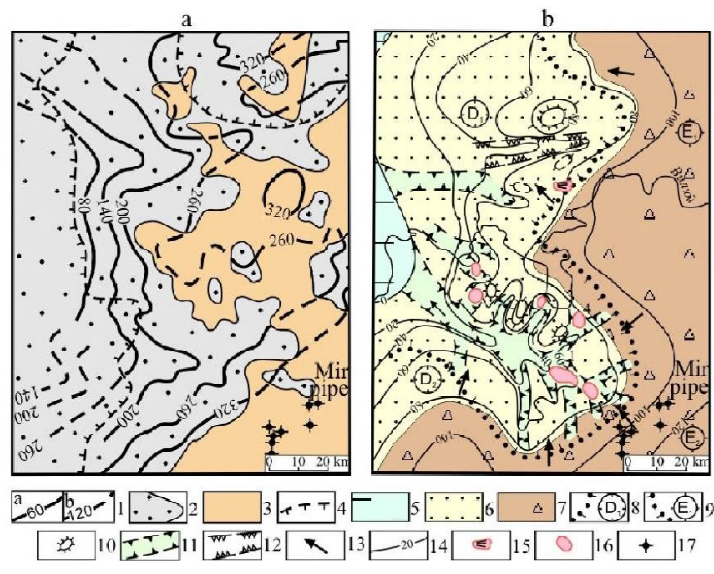

Fig. 3. Map of relief of kimberlite-hosting base surface in modern view (a) and its paleogeomorphological interpretation (b) after reconstructions carried out for Middle Carboniferous stage of formation of KIM dispersion haloes and diamond placers.

Reconstruction of buried or eroded surface relief back to "productive" levels prior to burial allows interpretation of the history of its development, to trace the evolution of transportation avenues of diamond-bearing sediments and, in a number of cases, to outline the location of primary sources or placers. Performing reconstructions of the most ancient and therefore the most transformed paleorelief of a kimberlite-hosting base (KHB) should be singled out as a first priority task.

Structural analysis of longitudinal profiles of ancient reconstructed river valleys and their gradients has special significance for renewal of evolutional development of relief. The gradients characterize dynamics of reliefforming processes, which is directly related to the depth of denudation of primary sources and transportation distance Paleozoic diamond-bearing rocks; 3-4 - sites of paleorelief transformation: 3 - completely destroyed by denudation, 4 - due to embedding of Early Triassic dolerite intrusions; 5-13 - forms of reconstructed paleorelief: megaforms $(5-$ low accumulative plain, 6 - slightly elevated denudation-accumulative plain, 7 - elevated denudation plain); macroforms (8- depressions, 9 - elevations); mesoforms (10 - denudation remnants, 11 - floors of main Late Paleozoic river valleys, 12 - tectonic depressions); 13 - main directions of transportation of kimberlite minerals; 14 - contours of reconstructed relief of KHB surface, in meters; 15-16 - morphogenetic types of KIM dispersion haloes (15 - deluvial taluses, 16 - alluvial in upper parts of paleovalleys); 17 Middle Paleozoic kimberlite bodies of KIM and their break-down products. Values of denudation of buried kimberlites and rocks of the KHB are assessed with application of the method of "summit plains".

Facies are combined into three dynamic types of deposits where sediments formed in various conditions under the effects of different intensity hydrodynamic forces (active, lowactivity, passive). Dynamic conditions of sedimentation control relative speed, pathway and duration of detritus transportation. Particle-size distribution of sandy fractions, median, skewness, and excess all reflect speed and mode of transportation. Relative duration of transportation may be characterized by sorting levels of sediments. Deposits of various dynamic types were formed in fundamentally different basin and continental conditions.

Dynamically active environments are most favourable for formation of haloes with increased content of kimberlite minerals. Formation of alluvial and beach deposits of KIM are examples. Less favourable are low-activity dynamic conditions, in which deluvial haloes were formed.

Dispersion haloes do not form in the passive dynamic conditions of static environments.

Depending on the position of KIM haloes in the paleorelief and the corresponding facies of the terrigenous rocks formed, morphogenetic types of haloes of various ranks can be distinguished. Morphogenetic type is a concentration of kimberlite minerals in terrigenous rocks, which occupying certain paleogeomorphological positions, characterized by a particular sedimentary facies and sedimentation dynamics defined by conditions of 


\section{0 $^{\text {th }}$ International Kimberlite Conference, Bangalore - 2012}

bedding, structure, mineral and grain-size distribution of KIM.

Morphogenetic research of KIM dispersion haloes provides the study of not only the compositions of pyropes, picroilmenites, chromespinels and other kimberlitic minerals but their peculiarities caused by exogenous factors as well: size, thickness and morphology of halo, KIM content, grain sizing, sorting, mechanical erosion of grains and others. Distinctive characteristics of haloes fingerprint the various morphogenetic types, and this enables one to distinguish the kind of diamond source (primary or sedimentary) and to evaluate the distance of transportation of kimberlitic minerals.

Data available on contents and KIM classes in continental and basin haloes show specifics of their formation (Fig. 4). Haloes of the continental group generally preserve a reasonably close spatial relationship with sources of kimberlite minerals.

1-7 - forms of paleorelief: megaforms (1 low accumulative plain, low level, 2 - slightly elevated denudation-accumulative plain, intermediate level, 3 - elevated denudation plain, high level), macroforms ( $4 \mathrm{a}-$ depressions, $4 \mathrm{~b}$ elevations); mesoforms ( 5 - floors of main Late Paleozoic river valleys and their thalwegs, $6-$ denudation remnants expressed in relief - a, flooded by basin waters $-b$ ); 7 - contours of reconstructed relief of KHB surface, in meters; 8 - coast lines of basin: a -minimal level of regressive phase, $b$ - maximal level of transgressive phase; 9 - axis of main watershed; 10 - main directions of transportation of kimberlite minerals: $\mathrm{a}$ - general, $\mathrm{b}$ - local (along main paleovalleys); 11 - directions of basin transgression; 12 -generalized contours of KIM dispersion train (haloes - more than $100 \mathrm{gr} / 10$ 1); 13 - kimberlite bodies.

KIM contents drop orders of magnitude at a distance of a few kilometers from sources. The sites of local erosion of ancient diamond-bearing rocks are fixed by anomalously highly worn KIM grains in haloes of continental genesis.

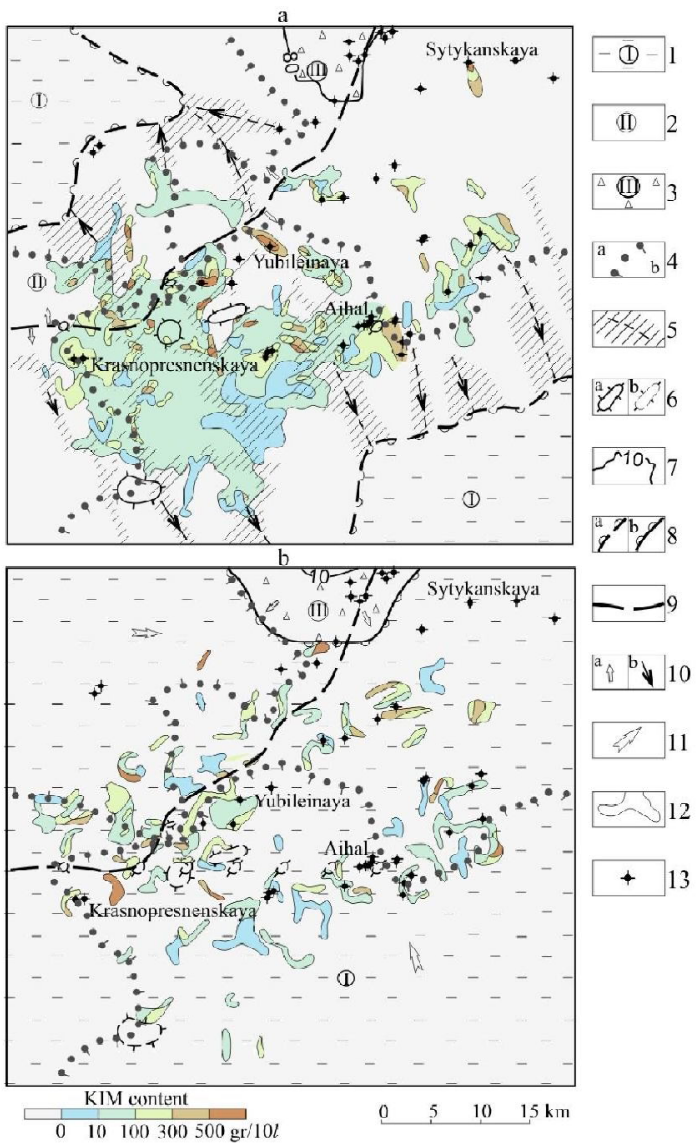

Fig. 4. Specific structural features of Late Paleozoic (a) continental and (b) basinal KIM dispersion haloes of paleodepressions and paleoelevations (example shown is of Alakit-Markha kimberlite field, Siberian platform).

Beach dispersion haloes, in spite of insignificant distance from KIM sources, do not display spatial relationship with primary sources. Their concentration is stipulated by position of ancient coast lines and favorable forms of relief.

The character of grain morphology and the polymineral nature of many KIM do not correspond to the existing concepts about dominance of highly eroded, monomineralic kimberlitic grains. Nevertheless, the mechanisms of waveaction and surf flow during short-term Late Paleozoic transgressions in some cases led to high concentrations of KIM in dynamic beach zone environments and loss of spatial connection with sources. 


\section{0 $^{\text {th }}$ International Kimberlite Conference, Bangalore - 2012}

Conditions of buried KIM dispersion haloes formed in buried territories differ from known Cenozoic ones, formed at the stage of the newest tectonic development within open areas, by significantly smaller distances of kimberlite minerals transportation and fast drop of KIM contents with increasing distance from sources.

\section{RESULTS OF THE RESEARCH}

On the basis of lithologic, stratigraphic, mineralogical, facies dynamic, paleogeo morphologic and morphogenetic features, three types of covered territories with buried kimberlite fields reflected in post-kimberlitic terrigenous diamond-bearing rocks are distinguished: slightly eroded fields with local KIM trains, moderately eroded fields with areal KIM trains and highly eroded fields with regional trains (Fig. 5).

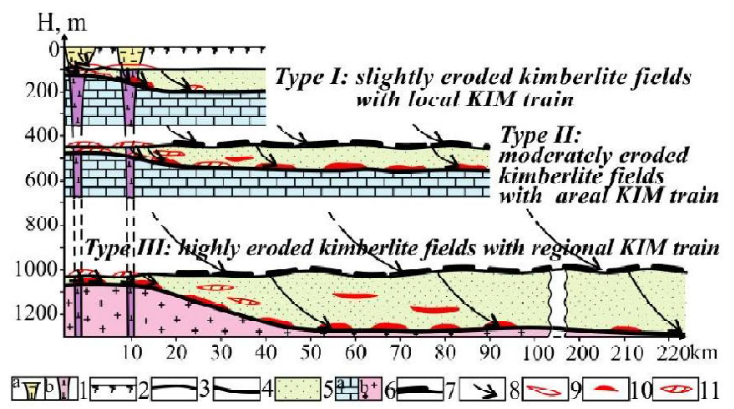

Fig. 5. Types of buried kimberlite fields in terrigenous diamondbearing rocks on closed territories.

1 - facies of kimberlite bodies and related rocks: a - crater, 1 -diatreme; 2 - present day surface at the time of primary sources emplacement; 3 - planation surface of the last relief development stage; 4 - buried surface of kimberlite-hosting base; 5 -terrigenous diamondbearing rocks; 6 -rocks of kimberlitehosting base: $\mathrm{a}$ - platform cover, $\mathrm{b}$ - crystalline basement; 7 reconstructed KIM dispersion train on the surface of denudation plane; 8 - dominating directions of kimberlite minerals redeposition; 9-11 - KIM dispersion haloes and diamond placers: 9 primary (result of denudation of kimberlites and related rocks), 10 - secondary (result of redeposition of KIM from terrigenous rocks), 11mixed (multiple sources).

Type I: slightly eroded kimberlite fields with local KIM dispersion trains. Denudation depth of buried primary sources for which the crater zone or the top part of the diatreme part is partially intact, constitutes tens to at most a first hundreds of meters. The area of KIM dispersionin sediments, represented by formations of one cycle of terrigenous sedimentation only slightly exceeds the area of the primary sources. The number of productive horizons in terrigenous rocks does not exceed 3-4. The thickness of the strata containing KIM dispersion haloes is comparable with amplitudes of reconstructed relief and constitutes about 40-60 m. In environments of type I territories mainly primary (kimberlitic source) and mixed (kimberlitic and terrigenous rocks sources) dispersion haloes are formed, with a distance from primary sources of not more than 10-20 km. Mineral compositions of KIM correspond to an association of kimberlite minerals in the sources. Erosion sites of terrigenous diamond-bearing rocks are fixed by "windows" with increased degree of KIM erosional wear. Mechanical wear on diamonds is practically absent. Areas of type I provide for carrying out prospecting aimed at mostly intact primary sources and diamond placers of short transportation distance.

Type II: moderately eroded kimberlite fields with areal KIM dispersion trains. These are characterized by completely eroded crater zones and truncated diatreme tops. The amount of the eroded material constitutes the first few hundreds of meters. The KIM distribution area exceeds that of the primary sources by at least an order of magnitude. General lengths of KIM transportation in areas of this type amounts to $100 \mathrm{~km}$ and more. Diamond placers of short and medium distance transportation are known. Within the areas of type II, prospecting situations become more complicated. A greater portion of the KIM dispersion haloes was formed due to erosion of 


\section{0 $^{\text {th }}$ International Kimberlite Conference, Bangalore - 2012}

more ancient terrigenous rocks, and haloes of mixed type occur mainly at relatively short distances (1-20 km) from the primary sources. In such environments, together with reconstruction of the general paleogeographic situation and determination of morphogenetic halo types, it is necessary to perform diagnostics to sort out the diamond source type. Secondary haloes (only terrigenous rocks sources) can not be used for direct discovery of primary sources. Investigation of paleogeographic conditions of their formation will lead to discovery or delineation of ancient terrigenous diamondbearing rocks or placers of diamonds.

In covered territories of type II, exploration should be directed at discovering primary and placer deposits, both 10th International Kimberlite Conference, Bangalore - 2012 Extended Abstract 5 of which may be of commercial interest. Among placers the deposits of short and medium distance transportation will dominate.

Type III: highly eroded kimberlite fields with regional KIM dispersion trains. These include kimberlite bodies represented by the lowermost parts of diatremes or by root zones. Denudation depth is always assessed to be hundreds of meters, often reaching $1000 \mathrm{~m}$ or more. Diamondiferous fields on the northern slope of Congo synclinorium, located within the Mouka-Ouadda and Carnot-Berberati regions of Central Africa, may serve as examples of areas with highly eroded primary sources, where Proterozoic kimberlites are expected.

The territories are characterized by extremely long (hundreds of $\mathrm{km}$ ) trains of diamonds distributed in terrigenous rocks, which is two to three orders of magnitude larger that the areas occupied by the primary sources. The thickness of strata with a great number of diamondiferous horizons is measured from tens to hundreds of meters. In Central Africa at 40-50 $\mathrm{km}$ distance from primary sources diamond placers are already characterized by the complete absence of other kimberlite minerals, due to multiple redeposition cycles and chemical erosion processes. The greater part of the diamonds preserves traces of mechanical chipping and attrition.

The placers were formed due to erosion of more ancient terrigenous rocks, including facies of short, medium, or more seldomly long distances of transportation. Significant time periods (hundreds of million years) of relief planation is a characteristic feature of the evolution of the highdenudation fields. The time of formation of the most ancient deposits is greatly separated from the time of primary rock' formation, being located in the area of active denudation on high plains.

Areas of type III are characterized by the most complicated exploration environments. The significant erosional depth of kimberlite bodies translates to a greater number of stages of redeposition, resorting and large total distances of transportation of diamonds and other minerals from primary sources. Significant proportions of the primary sources of the diamonds were transformed into placers. Delineation and determination of kimberlite bodies and related rocks, characterized by areas of type III and especially if small in size, is extremely complicated. The main diamond prospects are related to placer deposits. In such areas, the means spent on prospecting for primary deposits, as a rule, economically do not pay for themselves.

\section{CONCLUSIONS}

Application of the suggested assessment criteria for terrigenous diamond-bearing rocks make it possible to perform zoned exploration of covered regions of ancient platforms according to the types of kimberlite fields expected. Separating covered territories into various types enables targeted exploration with the proper methods for the discovery of diamond deposits of particular origin. 


\section{0 $^{\text {th }}$ International Kimberlite Conference, Bangalore - 2012}

Complex research of terrigenous rocks may be effectively used at different stages and scales $(1: 1000000-1: 10000$ scales $)$ of prediction and exploration work.

\section{References}

Ross, A.C. and Ross, J.P.R. (1985) Late Paleozoic depositional sequences are synchronous and worldwide. Geology, V. 13, ! 3, pp. 161-224.
Ross, A.C. and Ross, J.P.R. (1988) Late Paleozoic transgressive-regressive deposition. Sea-level changes: an integrated approach. Society of economic paleontologists and mineralogists: Special publication, ! 42, pp. 227-247. 